\title{
LA MIRADA JURÍDICA SOBRE LOS ANIMALES: UN ANÁLISIS DE SU ESTATUTO EN EL DERECHO PRIVADO ARGENTINO
}

[The legal view on animals: an analysis of its statute in argentine private law]

\author{
María VALERIa Berros* \\ Victoria HAIDAR** \\ Marianella GALANZINO***
}

\section{RESUMEN}

Este trabajo se propone explorar el modo cómo son regulados los animales no humanos al interior de derecho privado argentino. El estudio se concentra en los códigos civiles, en virtud del rol central que los mismos desempeñan en el sistema jurídico. Se

\section{ABSTRACT}

This paper aims to explore on how non-human animals are regulated in the Argentinian private law. The focus of this study is centered on civilian codes, considering their main role in the legal system. The objective is to establish the statute that is

RECIBIDO el 11 de mayo y APROBADO el 02 de noviembre de 2016

* Doctora en Derecho UNL. Profesora de Derecho Civil II e Introducción a la Sociología de la Facultad de Ciencias Jurídicas y Sociales de la Universidad Nacional del Litoral. Dirección postal: Centro de Investigaciones en Derecho, Facultad de Ciencias Jurídicas y Sociales, UNL. Cándido Pujato 2751, Santa Fe, CP: 3000, Argentina. Correo electrónico: vberros@fcjs.unl.edu.ar

** Doctora en Ciencias Sociales UBA. Profesora de Introducción a la Sociología de la Facultad de Ciencias Jurídicas y Sociales de la Universidad Nacional del Litoral. Dirección postal: Centro de Investigaciones en Derecho, Facultad de Ciencias Jurídicas y Sociales, UNL. Cándido Pujato 2751, Santa Fe, CP: 3000, Argentina. Correo electrónico: vhaidar@fcjs.unl.edu.ar

*** Becaria de Iniciación a la Investigación Científica de la Facultad de Ciencias Jurídicas y Sociales de la Universidad Nacional del Litoral. Dirección postal: Centro de Investigaciones en Derecho, Facultad de Ciencias Jurídicas y Sociales, UNL. Cándido Pujato 2751, Santa Fe, CP: 3000, Argentina. Correo electrónico: maygalanzino7@gmail.com 
procura establecer, mediante un análisis de las normas pertinentes, el estatuto que se confiere a los animales, así como indagar en sus matices. La primera parte del artículo pone el foco sobre el Código Civil redactado por Vélez Sarsfield, el cual rigió en el país entre 1869 y 2015. En la segunda parte la indagación se dirige hacia el recientemente sancionado Código Civil y Comercial.

Palabras claves

Derecho Privado - Sujetos de derecho - Animales conferred to non-human animals and to inquire on its nuances though an analysis of the pertinent rules. The first section of the article focuses on the Civil Code written by Vélez Sarsfield, which ruled over the country between 1869 and 2015. In the second section the investigation points towards the recently sanctioned Civil and Commercial Code.

\section{KEYWORDS}

Private Law - Subject of rights Animals

\section{INTRODUCCIÓN}

Entre la pluralidad de espacios en los que se pueden encontrar marcas, huellas, de los diferentes modos de concebir a la naturaleza, y con un énfasis especial a los animales, se encuentra el campo jurídico. Allí un conjunto de normativas de diverso tipo, que luego son interpretadas y aplicadas por los tribunales, traducen las representaciones que las sociedades tienen de la naturaleza y del vínculo entre naturaleza y sociedad.

En esta dirección, el derecho asigna, tanto a la naturaleza como a los animales, un determinado "estatuto": les atribuye una cierta entidad, los clasifica, prevé los efectos que se derivan de las relaciones entre los seres humanos y los animales, etc.

La determinación del modo cómo el derecho piensa a los animales, así como de la fisonomía que asume el régimen al cual los somete, son temas caros a las discusiones contemporáneas las cuales se nutren de insumos procedentes tanto del derecho ambiental y animal como de la ética, la teoría constitucional, etc.. Desde estos campos se han forjado, ya desde el siglo XX, un conjunto de argumentos que ponen en discusión la concepción que los cuerpos jurídicos de las sociedades occidentales poseen, históricamente, de la naturaleza y de los animales. ${ }^{1}$ Los aportes a

\footnotetext{
${ }^{1}$ Algunas contribuciones relevantes, entre muchas otras, que se han construído desde el campo de la ética: Francione, Gary, Animals, property, and the law (Philadelphia, Temple University Press, 2007); REgan, Tom, The case for animal rights (Californa, University of California Press, Berkeley \& Los Ángeles, 2004); Singer, Peter, Animal Liberation. Towards and end to human's inhumanity to animals (New York, HarperCollins, 1977); SINGER, Peter Libération animal ou
} 
los que nos referimos procuran justificar la modificación del lugar que se les confiere en la mayor parte de las regulaciones jurídicas, en las cuales se los piensa como objetos de explotación, o bien - y más recientemente de la mano del derecho ambiental - como objetos de protección, para pasar a considerarlos, por su valor inherente, en tanto sujetos de derecho.

Si bien este tópico ha adquirido mayor relevancia en las últimas décadas, no es novedoso para el derecho y, en particular, para el derecho privado. Así, hacia comienzos del siglo XX, juristas como René Demogue, entre otros, aludían a los animales al problematizar el concepto de sujeto de derecho.

Desde la perspectiva de este autor la categoría de "sujeto de derecho" no era más que un producto de la "técnica jurídica", que, con el desarrollo de la Modernidad se había investido valorativamente. Ello lo condujo a preguntarse por qué limitar la aplicación del derecho a la humanidad así como a reflexionar acerca de "cuán abominable" o generador, incluso, de "risas y descalificaciones" resultaba en su época, pensar en la posibilidad de que los animales fuesen sujetos de derecho. ${ }^{2}$ Prefigurando algunos de los debates actuales, Demogue sostenía que la verdadera preocupación debía consistir en preguntarse si la utilización de esa "regla técnica" podía conducir, en relación a los animales, a resultados deseables.

Más allá de la contribución del profesor francés, desde las últimas décadas del siglo pasado los aportes tendientes a revisar el estatuto jurídico de los animales no han cesado de proliferar. Así, se observan contribuciones que, también desde el campo legal, revisan la idea de sujeto de derecho.

Desde el clásico texto de Christopher Stone en el que se pregunta, de manera provocativa, acerca de la posible legitimidad procesal de los árboles, pasando por Marie-Angèle Hermitte que se interrogaba en similar período sobre un estatuto jurídico para la diversidad biológica, se observa una creciente discusión en este sentido. ${ }^{3}$

Actualmente, la prolífica generación de insumos para repensar este estatuto jurídico asume, en América Latina, una renovada centralidad. Países de esta región han decidido avanzar en el reconocimiento de la naturaleza

droits des animaux? en AfFeIsSA, Hicham-Stéphan - JeangÈne Vilmer, Jean-Baptiste (editores) Philosophie animale. Différence, responsabilité el communauté (Paris, Vrin, 2010); TAYLOR, Paul, Respect for nature. A theory of environmental ethics (Princeton, Princeton University Press, 1989).

2 Demogue, René. Notions fondamentales de droit privé. Essai critique (Paris, Libraire nouvelle de droit et de jurisprudence, 1911), p. 358.

${ }^{3}$ Hermitte, Marie- Angèle, Le statut de la diversité biologique en Droit et société, $\mathrm{N}^{\circ} 10$ Pratiques de recherche, questions théoriques et problèmes épistémologiques sur le droit et la société (1988); STONE C. Should trees have standing? Toward Legal Rights for Natural Objetcs en Southern California Law Review. (1972) p. 450-501. 
como sujeto de derecho. Primero Ecuador, con su reforma constitucional de 2008 y, poco más tarde, Bolivia, a través de la Ley No 71 que reconoce los derechos de la Madre Tierra y de la Ley No 300 que articula dicho reconocimiento con el vivir bien. ${ }^{4}$ Dichas regulaciones, emergentes de los países andinos de América Latina agregan nuevos elementos a la discusión. Ello es así en virtud de la explícita articulación que se establece, en aquellos contextos nacionales, entre esos cambios en el derecho y un programa que se presenta como alternativo al capitalismo. Así, los debates sobre el buen vivirlvivir bien ${ }^{5}$ intentan colocar entre signos de pregunta algunos conceptos como el de desarrollo y progreso, así como dar cuenta no sólo de la diversidad natural y cultural sino, también, de los heterogéneos espacios de producción de conocimientos que, de cara a la problemática ecológica actual, asumen especial relevancia.

Es preciso señalar, por otra parte, que estas indagaciones han comenzado a circular desde los mencionados países del sur hacia otros de la región mediante la presentación de proyectos de ley en similar sentido. Han transitado hacia la esfera del derecho internacional y hacia otras regiones en las que comienzan a detectarse iniciativas que nutren este proceso. ${ }^{6}$ Así, verbigracia, el reciente proyecto de ley sobre derechos de la naturaleza presentado en Argentina en julio de 2015; las resoluciones que, desde 2009, la Asamblea General de Naciones Unidas emite bajo el título "Armonía con la Naturaleza"; 7 a lo que se suman propuestas ciudadanas como la que impulsa, bajo la forma de iniciativa ciudadana europea, un proyecto de directiva comunitaria a ser impulsado bajo la modalidad de iniciativa ciudadana europea.

Es así pues que en algunos de los sistemas jurídicos de América Latina

${ }^{4}$ En el desarrollo del trabajo se hará referencia a las reformas legales mencionadas.

5 Estos conceptos no se encuentran exentos de disputas en relación a su significancia, origen y contenido. LE QUANG, Mathieu \& Vercoutère, Tamia. Ecosocialismo y buen vivir. Diálogo entre dos alternativas al capitalismo (Quito, Cuadernos Subversivos, IAEN, 2013)

${ }^{6}$ Sobre este proceso de circulación puede verse un trabajo anterior : HAIDAR, Victoria - Berros, María Valeria, Entre el sumak kawsay y la "vida en armonía con la naturaleza": disputas en la circulación y traducción de perspectivas respecto de la regulación de la cuestión ecológica en el espacio global en Revista Theomai. Estudios Criticos sobre Sociedad y Desarrollo, Año 15, № 32, (2015) p. 128-150.

7 Resoluciones ONU “Armonía con la Naturaleza”: Res. 64/196 (2009), 65/164 (2010), 66/204 (2011), 67/214 (2012), No68/216 (2013), No 69/224 (2014); Informes Secretario General de ONU "Armonía con la Naturaleza": A/65/314 (2010), A/66/302 (2011), A/ 67/317 (2012); Estudio sobre la necesidad de reconocer y respetar los derechos de la Madre Tierra, Foro Permanente para las Cuestiones Indígenas, Consejo Económico y Social de la ONU, E/C.19/2010/4. 
se reconoce a la naturaleza como sujeto de derecho, mientras que otras regulaciones piensan a los animales en tanto seres dotados de sensibilidad. ${ }^{8}$ A estos desplazamientos se suman los debates actuales e interrogantes que, como los de Demogue, proceden del pasado.

Teniendo en cuenta la reciente sanción, en la Argentina, de un nuevo Código Civil en el año 2015, resulta útil preguntarse si las representaciones acerca de los animales, que proceden de nuestro derecho civil, se han modificado o han permanecido iguales a lo largo de las décadas.

Así, el presente trabajo se concentra en analizar el derecho privado, espacio en el que se ha construido y consolidado el concepto de "sujeto de derecho", primero considerando a las personas físicas (o también llamadas de existencia física) y, más tarde, incorporando - no sin debates y oposiciones - a las personas jurídicas (o también denominadas personas de existencia ideal).

En este contexto, los códigos civiles asumen un rol medular a los efectos no sólo de reconstruir el estatuto jurídico que se reconoce a la naturaleza y a los animales sino, también, para indagar en sus matices.

Con esta finalidad en miras, la primera parte de esta contribución, se dedica a escrutar el Código Civil que, sancionado por Vélez Sarsfield, reguló desde 1869 hasta 2015 las relaciones civiles entre las personas.

En este documento confluyen normas que establecen una serie de reglas para la apropiación de elementos de la naturaleza, cuya gráfica más elocuente puede observarse, por ejemplo, en la serie de pautas para asegurar la propiedad de un panal de abejas que coloca de relieve la figura del propietario, persiguiendo, ese panal o bien al cazador siguiendo a su presa sin que medie interrupción para asegurar su dominio. A ello se suman, también, las reglas para solucionar conflictos por daños causados por animales, lo que es considerado como un sub-tipo al interior del sistema de responsabilidad por los hechos de las cosas.

Tanto las reglas de apropiación como el sistema de responsabilidad ponen de manifiesto un determinado estatuto jurídico, que no es sino la traducción jurídica de una determinada concepción de la naturaleza que es colocada como objeto susceptible de ser apropiado o bien, en el caso

${ }^{8}$ Los países en los que se ha reconocido como sujeto de derecho a la naturaleza en América Latina son Ecuador y Bolivia así como el Estado de Guerrero en México. A ello se suman una serie de propuestas legislativas en discusión en el caso de Argentina y algunas ciudades de Brasil. Por su parte, en el ámbito europeo, tanto a nivel supranacional como en algunos estados nacionales, se ha revisado el estatuto jurídico de los animales. Por ejemplo, en la Constitución de Alemania (2002), de Austria (2004), de Suiza (2000) así como en la reciente modificación legislativa en Francia que considera a los animales como seres vivos dotados de sensibilidad. 
específico de los animales, como objetos que "actúan” y sobre los que se deben establecer reglas claras para la determinación de responsables en los casos de producción de daños.

La segunda parte de este trabajo se enfoca en el nuevo Código Civil y Comercial que entró en vigor en 2015 en el que, también, se puede efectuar un similar análisis para indagar en las continuidades y rupturas o diferencias que son observables respecto de este tema. El debate por el estatuto jurídico de la naturaleza y de los animales no ha sido un eje en este proceso de reforma, lo cual se visualiza en la serie de normas que regulan, por ejemplo, el aseguramiento de la propiedad o la responsabilidad por el hecho de los animales. Sin perjuicio de ello, pueden identificarse algunas regulaciones, como el artículo 240, que introduce límites al ejercicio de los derechos, refiriéndose a la no afectación del funcionamiento ni la sustentabilidad de los ecosistemas de la flora, la fauna, la biodiversidad, el agua, los valores culturales, el paisaje, entre otros. Esto último permite matizar las traducciones legales y establecer diálogos entre las implicancias de la consolidación de un derecho privado que atienda a la dimensión colectiva y los aportes que, desde diferentes estrategias y espacios regulatorios, se identifican en los últimos años.

\section{UnA PRIMERA TRAdUCCIÓN: EL Código Civil DE Finales DEL SIGLO XIX}

Las normas que en el Código Civil redactado por Vélez Sarsfield’ (el cual rigió en el país durante más de cien años) se refieren a los animales no humanos expresan la filosofía social dominante hacia fines del siglo XIX. Producto directo de las ideas de la elite liberal-positivista que llevó a cabo la organización del Estado argentino, el Código Civil estableció las condiciones jurídicas para el enraizamiento y desarrollo de una economía de mercado y, en términos más generales, de una sociedad fundada sobre la ética liberal y sus ideas-fuerza: la libertad entendida en un sentido negativo, la responsabilidad individual por las consecuencias previsibles de los propios actos, la propiedad privada.

Expresión de la ideología imperante, el Código se encuentra embebido de una filosofía marcadamente liberal y racionalista; explicándose de esta manera el fuerte tinte individualista que nutre toda su concepción en torno a lo jurídico. Entre los institutos que representan esa matriz ideo-

9 Dalmacio Vélez Sarsfield (político y abogado), fue el redactor del Código Civil Argentino, aprobado por el Congreso de la Nación, sin modificaciones, en septiembre de 1869. El mismo entró en vigencia en enero de 1871. 
lógica dentro de su articulado se encuentran el "contrato", la "propiedad privada" y el principio de la "autonomía de la voluntad". La filosofía que traduce ese cuerpo normativo es, además, exclusivamente antropocéntrica. El hombre, entendido como "sujeto de derecho", se piensa como un fin en sí mismo que encuentra su único límite en la ley ${ }^{10}$.

Subyacía a esa poderosa maquinaria de configuración societal que fue el Código de Vélez, una fuerte confianza en el "progreso" y en las potencialidades creativas y transformadoras de los individuos. Si desde un punto de vista abstracto dicho cuerpo jurídico aportó el marco para la producción de un orden liberal, en términos concretos-históricos fue el instrumento normativo por excelencia del proyecto modernización que impulsaron -y narraron- los intelectuales, políticos, científicos, etc. que se encuadran, temporalmente, en la denominada "Generación del 80".

En este sentido, las normas que el codificador consagró, tanto a la regulación de las actividades productivas como a la resolución de los conflictos que se planteaban en el seno del espacio doméstico y, más ampliamente de la sociedad civil, tenían como correlato inmediato y directo las estrategias económicas que, con el correr de los años, configurarían el denominado "modelo agroexportador" (con la estructura social a él adscripta); no menos que la vida privada de aquella burguesía ilustrada que, en la mentalidad de Vélez, llevaba adelante la empresa civilizadora.

Las normas del Código Civil que se refieren a los animales están distribuidas en secciones que conciernen a dos ramas distintas del "derecho privado patrimonial": aquella que se consagra a la regulación de los derechos que los sujetos jurídicos pueden tener sobre las "cosas" ("derechos reales") y aquella relativa a la regulación de las consecuencias jurídicas de los hechos ilícitos, denominada "derecho de responsabilidad civil" o, más tarde, también denominado "derecho de daños". ${ }^{11}$

Dicha localización habla a las claras del estatuto del que gozan los animales no humanos en la legislación civil: son "cosas", bienes susceptibles

${ }^{10}$ Art. 1071 CC: "El ejercicio de un derecho propio o el cumplimiento de una obligación legal no puede constituir como ilícito ningún acto" (texto anterior a la reforma de la Ley No 17.711de 1968).

${ }^{11}$ Dentro de la estructura del Código Civil los derechos reales se encuentran regulados en el Libro III. Su Título V se ocupa del "dominio" de las cosas y sus modos de adquirirlos; consagrándose el capítulo I de dicho título a la "apropiación" (artículos 2525 a 2566). El derecho de la responsabilidad civil se encuentra regulado en el Libro II, De los Derechos Personales en las Relaciones Civiles. En el capítulo I, específicamente, se alude a los daños causados por animales (artículos 1124 a 1131) en el Título IX, que se dedica a las obligaciones que nacen de los hechos ilícitos que no son delitos. 
de valor económico ${ }^{12} \mathrm{y}$, específicamente, "semovientes", cosas que pueden transportarse de un lugar a otro, moviéndose por sí mismas (art. 2318 CC). De este modo, el Código Civil argentino, al igual que el Código francés de Napoleón, se ha mantenido fiel a la concepción del "animal cosa" (resse moventes), heredada del derecho romano y que resulta afín con el antropocentrismo cristiano. Queda expuesto, con claridad, el tratamiento instrumental que les confiere el Código, ya que no se los protege por su valor intrínseco sino en tanto y en cuanto permitan obtener ventajas patrimoniales al ser utilizados.

Como objetos que están en el comercio, los animales aparecen enrolados en relaciones jurídicas de carácter real o contractual. Sobre ellos recae y se ejerce el "dominio", esto es, la propiedad privada.

Asimismo, los propietarios de los animales son responsables, como enuncia el art. 1124 del CC, de los daños que los mismos causaren a terceros. Existen dos interpretaciones que, entre los expertos en derecho civil, se disputan la explicación de esta clase de responsabilidad. Para algunos autores dicha responsabilidad es subjetiva y encuentra fundamento en la "culpa" del dueño por la falta de vigilancia o de cuidado adecuado del animal ${ }^{13}$.

La segunda postura, mucho más generalizada en la jurisprudencia y entre los tratadistas de derecho civil a partir de la reforma de la Ley No 17.711 (la cual introdujo en el Código la responsabilidad "objetiva") ${ }^{14}$, viene a reforzar, de manera directa, la concepción "cosificada" de los animales. Desde este punto de vista, el fundamento se encuentra en los riesgos que, al igual que otras cosas (así, por ejemplo, los automóviles) entrañan, en determinadas situaciones, los animales y por los que, en la medida que se aprovechan de ellos, los propietarios deben responder ${ }^{15}$. En

${ }^{12}$ En la redacción original que le dio Vélez Sarsfield, el art. 2311 CC establecía que las cosas eran los "objetos corporales" susceptibles de tener valor. Con la reforma que introdujo, en el año 1968, la Ley No 17.711 al Código Civil, la redacción se cambió, estableciéndose que son cosas los objetos "materiales" susceptibles de tener un valor.

13 Llambias, Joaquín, Manual de Derecho Civil. Obligaciones (Buenos Aires, Abeledo Perrot, 1997)

${ }^{14}$ Este tipo de responsabilidad de funda en la idea del riesgo; si el propietario o tenedor del animal se beneficia con su utilización, está en el deber correlativo de asumir el riesgo que ello representa. SAGARna, Fernando, Responsabilidad civil por daños causados por animales (Buenos Aires, Depalma, 1998)

15 Tal es el caso, frecuentemente contemplado en los tribunales, de la responsabilidad que les incumbe a los propietarios de los animales que sueltos a la vera de las rutas, los cuales representan un riesgo para los conductores de vehículos y que, en algún fallo ha sido homologado directamente a la hipótesis de colisión 
ese sentido, las sentencias que encuadran esta especie de responsabilidad en el campo de la responsabilidad objetiva están pobladas de referencias a los animales como "cosas"16.

Si bien formuladas de manera abstracta para (de acuerdo a la racionalidad formal que inspira el derecho moderno) dar respuesta satisfactoria a expectativas de conducta futuras, las reglas que refieren, en el Código sancionado en 1869, a los animales no humanos, están impregnadas por el lenguaje de la época. Reproducen, así, de manera depurada, "cuadros" y "escenas" de lo que era, en la Argentina de fines del siglo XIX, una economía -y, más en general, una trama societal- orientada a la producción y comercialización de materias primas. ${ }^{17}$.

Así, las especies animales que (aun sin nombrarlas) Vélez tenía en mente al regular, en la sección correspondiente del Código, los modos de adquisición o extinción del derecho de dominio, eran tanto aquellas que estaban incorporadas y participaban del modo familiar y/o económico de organización de la vida humana que conformaba la "casa"/el "fundo" como aquellas que (aun cuando podían encontrarse, materialmente, dentro de los límites del fundo), llevaban una existencia independiente de los hombres.

De este modo, el orden impuesto por la "casa", por la organización inicialmente familiar de la existencia, que constituía un emblema de la civilización, fungía como criterio para la clasificación jurídica de los animales.

entre dos automóviles. "En los supuestos de accidentes de tránsito ocurridos en razón de la presencia de animales sueltos en la vía pública, el articulado legal que ordena este tipo de situaciones surge del art.1124...La responsabilidad emergente se funda en la teoría del riesgo creado, equiparándose dicha situación a la colisión de dos automóviles" (Cámara Civil, Comercial, Laboral y de Paz, Curuzú Cuatiá, 1994/08/19, Jurisprudencia Argentina, 1994-IV-485)

${ }^{16}$ Entre otras muchas sentencias, pueden consultarse: Cámara Civil y Comercial de la 3ra Nominación de Córdoba, 2007/10/18, La ley online.

${ }^{17}$ Con anterioridad a la sanción del Código Civil, Valentín Alsina redactó, en 1865, el Código Rural de la Provincia de Buenos Aires, el primero en su especie, a los fines de atender "a las más urgentes necesidades a satisfacer por la legislación rural". Allí se introducen una serie de regulaciones que procuran regular la propiedad de los animales que se utilizan para las labores agrícolas. El denominado régimen de "Marcas y Señales", introducido en el Código Rural de Alsina, configura un sistema útil y fiel a la demanda de contribuir al desarrollo agrícola-ganadero. La marca es el estampado a fuego, en el cuero visible del animal, que responde a ciertos dibujos inscriptos como una propiedad del título en los registros que llevan las provincias. Por otro lado, la señal consiste en la incisión hecha en la mayoría de los casos, en la oreja o nariz con un cuchillo. La marca y la señal importan, pues, el medio de identificación colectivo exigido para reguardar la propiedad del ganado, ya que en el caso específico de la marca, "indica y prueba acabadamente y en todas partes la propiedad del animal u objeto que la lleva” (Enciclopedia Jurídica Omeba, 1955). 
El Código echa mano, en forma implícita, a una tradición corriente en el derecho romano ${ }^{18}$, que clasificaba a los animales en "domésticos", "domesticados" y "salvajes" ("mansos", "fieros" y "amansados" en la antigüedad). Mientras las dos primeras categorías estaban inscriptas en el régimen de la civilización (en las formas de relación características del mundo humano), el universo de referencia para los animales "salvajes" era la naturaleza. "Salvajes" se consideraban, así, los animales que vivían "naturalmente libres", sin dependencia del hombre.

Por el contrario, se reputaban animales domésticos aquellos que se criaban en una casa (domus) y vivían en compañía del hombre, sin dificultad. Por su parte se entendían "domesticados" los animales que, siendo de naturaleza salvaje, podían acostumbrarse a vivir en compañía del hombre y servirle para ciertas tareas (Enciclopedia Jurídica Omega, 1954a). La domesticación implicaba, para los animales, la pérdida de sus manifestaciones agresivas; de allí que, para mantenerlos bajo la dependencia humana no se requerían castigos ni amenazas (Enciclopedia Jurídica Omega, 1954b). Sin embargo, si perdían el hábito de vivir bajo la dependencia del hombre volvían a ser reputados "salvajes".

Es preciso destacar que más allá de fungir como antónimo de "doméstico", lo "salvaje" asumía en el Código dos significaciones. Una es amplia y remite, como antes mencionamos, a las especies animales que escapan al régimen de las relaciones humanas, cuyo modelo era el domus, la casa. Desde este punto de vista, los “animales salvajes", en oposición a aquellos "domésticos" y "domesticados", son aquellos que desarrollan su existencia en un estado de libertad que el codificador calificaba de "natural".

Pero, asimismo, Vélez parece utilizar la expresión "animal salvaje” para aludir a los “animales bravíos" (art. 2527 CC) y "feroces” (art. 1124 CC); esto es, para connotar no sólo un modo de existencia ajeno a la regimentación característica de la civilización (esto es a la domesticidad) sino, asimismo, a un sub-conjunto de animales que exhibían, frente al hombre, un comportamiento agresivo, feroz ${ }^{19}$.

${ }^{18}$ Esta clasificación, contenida entre los artículos 1124 y 1131 del Código Civil vigente hasta el 31 de julio de 2015 en Argentina, también estaba contemplada en la que fuera la principal fuente en la que se inspirara Vélez Sarsfield para redactar el Código Civil, el denominado Esboço de Freitas. A saber, art. 4085 del Esbozo de Freitas establecía que eran susceptibles de apropiación (...) todos los animales bravíos, cuadrúpedos o volátiles, y los domésticos que recobraren su antigua libertad, o perdieren la costumbre de volver a la residencia de su dueño, mientras que el artículo 4086 inc. $2^{\circ}$ prescribía que eran susceptibles de apropiación los animales domésticos y domesticados aunque huyan y se acojan en predio ajeno" (Código Civil Proyecto, A. T de Freitas, 1901)

19 Además de emplear el término "bravío" como sinónimo de "salvaje” en el art. 
Esta segunda significación, en virtud de la cual pueden atribuirse a los animales ciertos rasgos psicológicos característicos, asimismo, de los seres humanos, está autorizada por la polisemia del término "salvaje", cuando este funciona, como sucede en el Código Civil, como antónimo de doméstico. Tanto los especialistas en derecho civil como los jueces han asociado la noción de "animal feroz" con la imagen de animales de "instintos crueles y sanguinarios" que pueden resultar peligrosos para el hombres, más allá de cualquier domesticación accidental ${ }^{20}$.En todo caso, la ferocidad de un animal siempre se piensa en relación al peligro que el mismo puede engendrar para el hombre (C.Civ.y Com. Trenque Lauquen, 1991/02/12).

La clasificación a la que antes referimos, entre animales domésticos, domesticados y salvajes, organiza, al mismo tiempo, las formas a través de las cuales una persona puede convertirse en dueño de un animal. Para los animales salvajes, la "apropiación"-con sus sub-especies "caza" y "pesca"- es el modo de devenir propietario.

En este sentido, el Código Civil proporcionó el andamiaje jurídico para auténticas prácticas de "apropiación originaria" de los animales que, viviendo en su "libertad natural" (art.2540 CC), ajenos a la sociedad, eran considerados, en términos jurídicos, res nullius, esto es, "cosas sin dueño". Esta última categoría, que procede del derecho natural ${ }^{21}$, es el resultado de la puesta en movimiento de la cosmovisión dualista y antropocéntrica que funda el de derecho natural, inaugurando la división que ha conducido a la proclamación del hombre como "animal razonable", sujeto de derecho, "dueño y poseedor de la naturaleza"22

De acuerdo a la racionalidad dominadora y productivista, puesta de

2527 que se refiere a la apropiación, el adjetivo "feroz" aparece, significativamente, en el artículo 1124 CC consagrado a regular la responsabilidad por daños causados por los animales.

${ }^{20}$ Cifuentes, Santos, Código Civil Comentado y Anotado, t. II (Buenos Aires, La Ley, 2008, P. 709).

${ }^{21}$ El Derecho matural es una corriente filosófica que pondera la existencia de un derecho anterior a cualquier otro y que es común a todos los pueblos y épocas, ello en virtud de ser inherente a la naturaleza humana y por lo tanto es superior a cualquier derecho positivo. TUCK, Richard Natural Rights Theories: Their Origin and Development (Cambridge University Press, 1982). "Naturaleza se opone a cultura. La primera, en sentido lato, comprende lo que al hombre es dado; la segunda, lo que el hombre ha hecho. Derecho Natural, es, por consiguiente, el Derecho que el hombre encuentra ya existente; y este Derecho Natural se distingue nítidamente del derecho que el hombre fabrica" Goldschmid, W. Introducción Filosófica Derecho, la teoría trialista del mundo jurídico y sus horizontes (Buenos Aires, Depalma, 1980)

${ }^{22}$ Burgat, Florence, Res nullius, l'animal est objet d'appropriation en Archives Philosophiques du Droit No 38 (1993) p. 279-289. 
manifiesto, acertadamente, por uno de los primeros comentaristas del Código $^{23}$, los objetos que no pertenecían a nadie sólo podían estar (en la vasta extensión de la pampa argentina, es la letra omitida) "esperando al primer ocupante"; en una suerte de estado de libertad natural destinado a ser suprimido por la voluntad de dominio característica de la especie humana.

Es que, en la inteligencia jurídica, lo que media entre el estado res nullius y el dominio es siempre alguna forma de violencia, un acto de aprehensión efectivo o potencial. Así, la propiedad de un animal podía adquirirse de manera material y directa (pescando, cazando) o bien a través de actos que, aunque no involucraran un contacto personal, pusieran al individuo en cuestión en presencia de la cosa, con la posibilidad física de tomarla, siempre que la intención "apropiadora" se manifestara de un modo visible y objetivo. Estaba claro que la posesión se podía adquirir no sólo con las manos sino con instrumentos específicos: redes, trampas, etc.

Así, mientras un cazador fuese persiguiendo a un animal previamente herido, aquel que lo tomase debería entregárselo (art. 2541 CC). El hecho de herir al animal exteriorizaba el animus adquisitivo de manera objeti$\mathrm{va}^{24}$. En otros casos, el solo hecho de perseguir, sin necesidad de herir, da cuenta, para la mentalidad del codificador, de la intención de mantener la propiedad. Leída desde la contemporaneidad, la descripción de esos actos de persecución reviste un sesgo cómico: "Las abejas que huyen de la colmena, y posan en árbol que no sea del propietario de ella, entiéndese que vuelven a su libertad natural, si el dueño no fue en seguimiento de ellas, y sólo en este caso pertenecerán al que las tomare" (art.2545 CC).

Forjadas al calor de la idea, orientada hacia el futuro, de "progreso", las normas que regulaban la adquisición del dominio a través de actos de apropiación constituyeron los medios con los que se instrumentó y/o se legitimó el señorío y aprovechamiento (en principio, ilimitado) que los seres humanos ejercieron sobre los animales.

Es a través de alguna forma de trabajo (captura, abatimiento, marcación, domesticación) que, como señala Burgat, las cosas que están a disposición de todos salen de esa condición de "estado común" para caer en la sujeción de un dueño. Así, en la medida en que aquello que determina la condición de "salvaje" es la existencia independiente del hombre, los animales que, aun cuando se encontraran en un terreno sujeto a propiedad privada, vivieran en "libertad natural", eran considerados res nullius. Ello también explica que si los animales domesticados -y otrora salvajes- recuperaban su

${ }^{23}$ Lafaille, Héctor, Curso de derechos reales, vol.2. (Buenos Aires, Ghio, 1925)

${ }^{24}$ Lafaille, Héctor, cit. (n. 23) p. 84. 
antigua libertad, el dominio sobre ellos se extinguía; salvo en las hipótesis en que, frente a la "huida", los dueños se lanzaran a la persecución de los animales.

Otro de los modos para adquirir la propiedad de los animales "domésticos" o "domesticados" era la accesión "moral" o "a término". El primer supuesto, contemplado en el art.2316 CC, comprende a los animales que, siendo en principio "cosas muebles" (que se mueven por sí mismas) se consideran "inmuebles" por accesión moral, esto es, porque el propietario del inmueble en cuestión las colocó intencionalmente en él, destinándolos al cultivo o al beneficio de la finca. Para los animales, esta forma de accesión que, en contraposición a aquella que supone adhesión "física", se denomina "moral", supone su relativa inmovilización. De este modo la "libertad natural" (que coincide, prácticamente, con la libertad de movimiento de la que gozan, en principio los animales) se restringe para quedar comprendida dentro del perímetro del terreno en cuestión.

Por otra parte, el Código preveía la posibilidad de la adquisición del dominio sobre animales domesticados por "aquerenciamiento". Si un animal "contraía la costumbre", decía Vélez, de vivir en otro inmueble, el dueño de este adquiría su dominio mientras que el antiguo dueño carecía de medios jurídicos para reclamar su recuperación o exigir una indemnización (art.2592). Se necesitaba un tiempo para justificar que esos animales habían contraído el hábito de quedarse en un terreno ajeno, ${ }^{25} \mathrm{de}$ allí la denominación de "accesión a término" 26 . A la inversa, esa propiedad podía perderse tanto si los animales (salvajes o domesticados) recuperaban su antigua libertad o "perdían la costumbre" de volver a la residencia de su dueño (art.2605).

Como puede observarse, al regular los modos de adquisición y pérdida de la propiedad sobre los animales, así como la responsabilidad civil por daños que ellos pudieran generar, el derecho civil reproduce y refuerza el antropocentrismo. La centralidad de lo humano encuentra sustento en la expulsión de lo animal hacia aquellas dos esferas que, desde la Modernidad, se erigen como "lo otro" de la sociedad: la esfera de las cosas y la esfera de la naturaleza.

El primero de esos dos ámbitos se corresponde con una categoría del derecho; justamente, aquella que viene a oponerse a la de "sujeto" o "persona". En tanto "cosas" los animales pueden, como vimos, ser objetos del dominio privado como fuente de responsabilidad por daños.

${ }^{25}$ Lafaille, Héctor, cit. (n. 23)

${ }^{26}$ Así, el Derecho civil sancionaba la negligencia del propietario, su falta de cuidado/vigilancia sobre el animal. 
Si bien no constituye, en sí misma, una tercera categoría jurídica, la "naturaleza" funciona, asimismo, como un marco referencial para pensar lo animal como límite exterior del mundo humano. Es aquel lugar primigenio del que los animales proceden y al cual pueden regresar huyendo, fugándose o soltándose; situaciones en las cuales (salvo las hipótesis de persecución) se extingue la propiedad sobre ellos. No carentes de toda violencia, esos desplazamientos adquieren el valor, "humano", de una liberación: a través de esos movimientos, los animales recuperan, según la letra de las normas, la "libertad natural".

La "libertad" (una libertad que nacería más allá de las fronteras de la civilización pero que, no obstante, se piensa en términos humanos), entendida como lo opuesto al encierro y al dominio, no es la única experiencia "psicológica", "ética” o "social” de las que, a pesar de su cosificación, los animales parecen gozar.

Es significativo que, para connotar aquello que corresponde al programa instintivo de los animales el Código Civil no utilice el término "instinto" sino aquel, mucho más ambiguo, de "hábito". En esta dirección, el art.1126 CC aclara que el dueño de un animal no se exime de responsabilidad porque el daño que el mismo hubiese causado "no estuviese en los hábitos generales de su especie". Como sabemos, la noción de "hábito" se utiliza para designar comportamientos humanos; aunque, (y de allí su ambigüedad) connota inclinaciones (o disposiciones, disposiciones, tendencias; el vocabulario varía según el dominio de que se trate) que están a horcajadas de lo "cultural" y lo "natural".

En todo caso, la idea misma de "especies animales" carece, en el Código, de contornos precisos. Al regular, en el art. $1124 \mathrm{CC}$, la responsabilidad del propietario por los daños que un animal causare a terceros, Vélez parece referirse a los daños causados por el "hecho del animal", entendido como un hecho imputable al régimen de los instintos, procedente de un "acto propio, instintivo, reflejo o natural, propio de la condición biológica del animal, sin intervención fáctica de la conducta del hombre" (CCiv.yCom. Moron, 2004).

Pero al mismo tiempo, al sostener en el art. 1126 que el propietario no se salva de su responsabilidad porque el daño causado por el animal "no estuviese en los hábitos generales de su especie", el codificador parece contemplar la posibilidad de que haya hechos, producidos por animales, que no se correspondan con los hábitos de su especie, esto es, que su comportamiento pueda escapar al régimen de los instintos. Se ilustra esta posibilidad del siguiente modo: "Sabemos que el perro muerde, que el caballo cocea, etc. lo que constituye los hábitos propios de la especie pero extraordinariamente el animal puede tener reacciones que no son las 
comunes de un animal de su especie, sea por la aparición de hábito que no pierden, por súbito enfurecimiento o por otras causas reservadas a las leyes de la naturaleza, no siempre conocidas. El Código Civil no distingue". (Enciclopedia Jurídica Omega, 1954b, P. 582)

Por otra parte, para complicar aún más las cosas, entre las reglas que regulan la adquisición y la pérdida de la propiedad sobre los animales Vélez no dejó de referirse a ellos como "seres de costumbres", capaces de aquerenciarse en un determinado lugar o de perder la costumbre de vivir donde antaño lo hacían.

Además del vector de "humanización" que significan estas referencias a los "hábitos" y las "costumbres", los animales también son connotados, en el derecho civil, con categorías psicológicas y morales correspondientes al mundo humano. Así, las reglas de distribución de la responsabilidad por los daños causados en el marco de peleas entre animales varían según el posicionamiento que cada uno de ellos asumiera en la pelea -"ofensor" u "ofendido" - y la conducta - "provocadora" o "reactiva"- que los mismos hubieran asumido. "El daño causado por un animal a otro, será indemnizado por el dueño del animal ofensor si éste provocó al animal ofendido. Si el animal ofendido provocó al ofensor, el dueño de aquel no tendrá derecho a indemnización alguna" (art. 1130 CC).

La idea de utilidad aparece, siempre, como un ordenador subyacente, que determina las consecuencias jurídicas de los actos en los que participan los animales y que se sobre-imprime y sustituye la ordenación que constituye, en sí misma, la especie. Como desde la perspectiva productivista, utilitaria, del derecho civil, se supone que quién es dueño de un animal extrae algún provecho de él, aun cuando este produzca daños que escapan a los "hábitos generales de la especie", el propietario es responsable. Paralelamente, el derecho sanciona a los propietarios "excéntricos", al sujeto que se aparta de las reglas de productividad características del mundo burgués, para poseer animales feroces que no le reportan ninguna utilidad, obligándolo a responder por los años que causare, aun cuando no hubiese sido posible evitar el daño y aunque el animal se hubiese soltado sin culpa (art. 1129 CC).

Desde la perspectiva jurídica, en tanto bienes con valor económico, los animales están, digamos "destinados a la explotación". El texto civil es elocuente, asimismo, al regular el derecho de "uso" de los animales que una persona puede adquirir al tomar posesión física de ellos: "Si se ha establecido sobre animales, el usuario tiene derecho a emplearlos en los trabajos y servicios a los cuales son propios por su especie y aun para las necesidades de su industria o comercio" (art. 2691 CC).

De este modo, la apropiación y el sometimiento de los animales al 
dominio humano parecen estar legitimados tanto por el aprovechamiento económico (rural, comercial o industrial) como por las necesidades ligadas al consumo familiar ${ }^{27}$.

Entre los supuestos contemplados específicamente por la jurisprudencia se anota el uso de animales para tareas rurales y, asimismo, para espectáculos comerciales como son las "jineteadas". En este último contexto cultural, los jueces han convalidado, incluso, el maltrato de animales con la justificación de que, de ese modo, brindan un mejor espectáculo. Así, la provocación de un equino mediante el uso de un rebenque, no constituye una imprudencia humana capaz de romper "el nexo causal entre el hecho de la bestia y el resultado dañoso [eximiendo, de ese modo, al propietario de su responsabilidad] sino precisamente la forma de lograr que ésta corcovee y brinde de esa manera su mejor esfuerzo y colaboración en el espectáculo que brinda la jineteada" (Cam. 1 ra. Civ.y Com. Bahía Blanca, Sala I, 1998/03/16).

Por otra parte, como antes señalamos, la apropiación por mero placer no está sancionada per se, sino sólo en el caso que de ello devenga un daño.

\section{Un SEgundo CUeRPo Normativo: El Código Civil y Comercial Unificado de 2015}

A partir de agosto de 2015 entró en vigor un nuevo Código Civil y Comercial unificado, versión revisada de un Anteproyecto presentado en $2012 . .^{28}$

El intento por modificar los principales cuerpos del derecho privado argentino no es nuevo, ha habido varios ensayos a lo largo del siglo XX pero, finalmente, recién en el siglo en curso se pudo debatir y aprobar un nuevo texto, lo que implicó una gran cantidad de discusiones entre las cuales, no obstante, la cuestión animal ha permanecido marginal.

Contrariamente a recientes reformas y leyes que, en otros sistemas jurídicos, han comenzado a pensar en un nuevo estatuto para el animal no

27 "El que tiene el derecho de uso sobre un rebaño, o piara de ganado, puede aprovecharse de las crías, leche y lana, en cuanto baste para su consumo y el de su familia" (art. 2962 CC)

${ }^{28}$ El nuevo Código Civil y Comercial es fruto del trabajo de la «Comisión para la elaboración del proyecto de ley de reforma, actualización y unificación de los Códigos Civil y Comercial de la Nación» creada por decreto presidencial 191/2011 y coordinada por Ricardo Lorenzetti como presidente, Elena Highton de Nolasco y Aída Kemelmajer de Carlucci. Allí se dio lugar a una primera versión, el Anteproyecto de Código Civil y Comercial de la Nación, que luego fuera reformado en parte de su articulado durante el proceso legislativo previo a su aprobación en 2014. Este cuerpo legal entró en vigor en agosto de 2015. 
humano a partir de conceptos como "ser sensible", "sintiente", "dotado de sensibilidad", en el caso argentino este no ha sido uno de los debates medulares. ${ }^{29}$ Por el contrario, en el espacio de audiencias que se desarrolló en torno a diferentes aspectos del código proyectado, la problemática se dejó de lado, identificándose sólo algunas referencias al tema. Verbigracia, la presentación de una ponencia en la que se indicaba la necesidad de incorporar un apartado específico que aluda a la consideración jurídica de los animales y que, de manera explícita, determine que no son cosas. ${ }^{30}$

Como se señaló anteriormente, al interior del derecho civil argentino, la cuestión animal ha transcurrido entre el problema de la propiedad y el de la responsabilidad, lo que se tradujo en una serie de normas, muchas de ellas, hoy en tensión con nuevas perspectivas que colocan el foco, sobre todo, en la necesidad de problematizar la propiedad sobre los animales. ${ }^{31}$

Este tema no fue uno de los tópicos en discusión sino que, por el contrario, se advierte que los animales siguen integrando el catálogo de cosas muebles no registrables (art. 1947 CCC)

En el caso de aquellos que son objeto de caza y pesca se los considera susceptibles de apropiación; lo que difiere en el supuesto de los animales "domésticos" o "domesticados" en los que la regla es la no apropiación ligada al ejercicio de dominio que, sobre ellos, se ejerce por parte de sus dueños.

Las reglas para determinar el dominio entre cazadores en pugna sobre el animal salvaje o aquel que, siendo domesticado, recupera su libertad

${ }^{29}$ Por ejemplo, la Constitución de Alemania (2002, art. 20a), de Austria (2004, art. 11.1), de Suiza (2000, art.80) así como la reciente enmienda de la Asamblea General en Francia sobre la consideración de los animales como seres vivos dotados de sensibilidad que viene a modificar el estatuto de "cosa" que el Código Civil les venía asignando (art. 515.14). A nivel regional, en la Unión Europea, se puede remarcar el Tratado de Ámsterdam (Protocolo sobre Protección y Bienestar de los Animales) y el Tratado de Lisboa (art. 13) que refiere de modo directo a la necesidad de tener en consideración el bienestar animal tanto en la formulación como en la aplicación de las comunitarias. Asimismo, la Constitución Europea de 2004 que, aunque no ha entrado en vigor, también prescribe la necesidad de considerar el bienestar animal y su calificación como seres sensibles. Se puede agregar, verbigracia, la reciente prohibición a nivel de la Unión Europea respecto de la experimentación animal para ingredientes cosméticos (Directiva 76/768/CEE).

${ }^{30}$ Ponencia presentada por estudiantes de la Facultad de Derecho y Ciencias Sociales de la UNC de la materia optativa "Derecho y Protección Animal" y la Sala de Derecho Animal del Colegio de Abogados de Córdoba. Directora: Dra. Wilma Andrea Heredia de Olazábal, Secretaria Académica: Dra. Eleana Casado en el marco de la Audiencia Pública sobre el proceso de reforma del Código Civil y Comercial desarrollada en la localidad de Córdoba el 4 de octubre de 2012.

${ }^{31}$ Francione, Gary, cit. (n.1) 
(art. 1947 CCC) sigue estando presente así como aquellas destinadas a delinear la adquisición del dominio sobre los peces obtenidos a través de la pesca en aguas de uso público (art. 1949 CCC)

También las reglas tendientes a salvar la propiedad sobre un enjambre de abejas que se moviliza (art. 1950 CCC) se advierten dentro de las hipótesis contempladas en la sección dedicada a establecer el sistema de apropiación para la adquisición del dominio en supuestos considerados especiales.

Asimismo, la nueva legislación continúa considerando el tema de la responsabilidad por el hecho de los animales como un supuesto de responsabilidad por el "hecho de las cosas" (art. 1759 CCC) aunque ya sin el conjunto de hipótesis particulares que, en el cuerpo anterior, versaban sobre la identificación, por ejemplo, del animal atacante para una consecuente individualización de consecuencias jurídicas respecto de la asignación de responsabilidades.

Si bien es claro que el debate por el estatuto jurídico de los animales no ha sido contemplado en este proceso de manera medular, también es interesante observar la incorporación de normas que, inspiradas en la necesidad de consolidar una dimensión colectiva del derecho privado, introducen algunos elementos importantes articulados con la cuestión animal. Se trata de nuevas contribuciones que pueden ser puestas en diálogo con los aportes que ponen en discusión el estatuto jurídico de los animales.

En ese sentido, se destaca la incorporación de un artículo conducente a limitar el ejercicio de los derechos individuales sobre los bienes. El artículo 240 establece: "El ejercicio de los derechos individuales sobre los bienes mencionados en las Secciones 1 y 2 debe ser compatible con los derechos de incidencia colectiva. Debe conformarse a las normas del derecho administrativo nacional y local dictadas en el interés público y no debe afectar el funcionamiento ni la sustentabilidad de los ecosistemas de la flora, la fauna, la biodiversidad, el agua, los valores culturales, el paisaje, entre otros, según los criterios previstos en la ley especial”.

Este artículo permite pensar en la apertura hacia traducciones legales que comienzan a desmarcarse del antropocentrismo, incluso, ya se ha afirmado que este sería un contenido bio-ecocéntrico al interior del nuevo código que se ocupa, en diferentes apartados, de cuestiones relativas al problema ecológico. ${ }^{32}$

Así, en el caso del derecho argentino, esto parece venir de la mano de una importante discusión que se desarrolló al interior del derecho privado

${ }^{32}$ Falbo, Anibal - Esain, José. El Código Civily Comercial y el ambiente en Revista Código Civil y Comercial La Ley Año 1. Nro 2 (2015) p. 19-24. 
a los fines de dar un giro que permita introducir su dimensión colectiva. Así, las contribuciones erigidas sobre los intereses supra-individuales, el debate sobre la función de la propiedad, entre otros, reciben su traducción al interior del nuevo cuerpo legal. El artículo citado puede observarse como una clara huella de este proceso y también permite, como mencionamos, engrosar el repertorio de líneas argumentales para el debate sobre el estatuto jurídico de lo no humano.

La discusión, si bien no fue central en la reforma de la legislación civil y comercial, no es menor si se considera tanto el contexto local como el regional.

En relación al primero, es importante apuntar que algunas decisiones judiciales han generado un mayor debate sobre este tema. Recientemente, Argentina ha sido uno de los primeros países que, a nivel jurisprudencial, reconoce a los animales no humanos como sujeto de derecho hacia fines de 2014 en el marco de la presentación de una acción de habeas corpus destinada a la liberación de una orangutana en el zoológico de Buenos Aires. ${ }^{33}$

El 18 de diciembre de 2014, la sentencia de la Sala II de la Cámara Federal de Casación Penal resolvió que correspondía tramitar el habeas corpus presentado en favor de la orangutana Sandra - que habita en el zoológico de la Ciudad Autónoma de Buenos Aires - a los fines de lograr su liberación. Esta resolución puede ser puesta en sintonía con aquellas que, más tarde, intentan también colocar el acento en este mismo problema. ${ }^{34}$

En la muy breve decisión de 2014 la Cámara sostuvo que: “...a partir de una interpretación jurídica dinámica y no estática, menester es reconocerle al animal el carácter de sujeto de derechos, pues los sujetos no humanos (animales) son titulares de derechos, por lo que se impone su protección en el ámbito competencial correspondiente (Zaffaroni, E. Raúl y et. al., "Derecho Penal. Parte General", Ediar, Buenos Aires, 2002, p. 439; también Zaffaroni, E. Raúl "La Pachamama y el humano", Ediciones Colihue, Buenos Aires, 2011, p. 54 y ss) ${ }^{35}$.

${ }^{33}$ Berros, María Valeria, Breve contextualización de la reciente sentencia sobre el habeas corpus en favor de la orangutana Sandra: entre ética animal y derecho en: Revista de Derecho Ambiental No 41 (2015) p. 154-163.

${ }^{34}$ Se destaca, por ejemplo, la sentencia Cámara de Apelaciones en lo Penal, Contravencional y de Faltas Causa No 17001-06-00/13 "Incidente de apelación en autos G. B., R. s/inf. Ley 14346” que, en noviembre de 2015, ante un caso de maltrato animal de más de sesenta perros, alude a la discusión de los animales como sujetos de derecho así como a su carácter de seres sintientes.

${ }^{35}$ Fragmento de la sentencia "Orangutana Sandra s/ recurso de casación" de la Sala II de la Cámara Federal de Casación Penal, 18.12.2014. En la segunda obra citada en el parágrafo Eugenio Zaffaroni sostiene que "A nuestro juicio, el bien jurídico en el delito de maltrato de animales no es otro que el derecho del propio 
Este planteo no es el primero que se realiza, por el contrario, la estrategia posee ya un relevante recorrido dando apertura a discusiones y posicionamientos en diferentes países y regiones del mundo.

En primer término en Brasil, en la ciudad de Salvador de Bahía, al discutirse ante la justicia la liberación de una chimpancé de nombre Suiza. Ella residía en el zoológico de Bahía y, aún cuando falleció durante el proceso judicial, se dictó una sentencia que la reconoció como portadora de derechos. ${ }^{36}$ Luego, en otros países, como Argentina, Estados Unidos, México en los que se desarrollan estrategias similares con divergente éxito. En el caso de Argentina se encuentran en curso planteos de similares características ante la justicia de las Provincias de Entre Ríos, Córdoba, Mendoza, Río Negro y Santiago del Estero, varios de ellos presentados por la misma organización que inició el habeas corpus en favor de la orangutana Sandra y que hoy se configura como su representante legal en el amparo en curso. ${ }^{37}$

Asimismo, y como expresamos en la introducción, en el contexto latinoamericano se identifican propuestas legales que - en particular desde Ecuador y Bolivia - contribuyen a enriquecer el debate por los derechos de "lo no humano" al haberse reconocido a la Pachamama, a la Madre Tierra, como sujeto de derecho.

Este innovador reconocimiento constitucional y legal, cabe señalar, no necesariamente se tradujo en una clara modificación respecto del estatuto de los animales en particular. ${ }^{38}$

Por el contrario, si bien el artículo 71 de la Constitución del Ecuador alude al Estado como el promotor del respeto de todos los elementos que integran el ecosistema y el artículo 73 refiere de manera expresa al problema de la extinción de especies, el artículo 281 que regula la soberanía alimentaria estima que será responsabilidad del Estado precautelar que los

animal a no ser objeto de la crueldad humana, para lo cual es menester reconocerle el carácter de sujeto de derecho". ZAFFARONI, Eugenio La Pachamama y el humano (Buenos Aires, Ediciones Colihue, 2012. p. 54)

${ }^{36}$ Habeas Corpus n. 833085-3/2005 da 9a Vara Crime da Cidade do Salvador, Bahia. Juiz Edmundo Lúcio da Cruz. Diário do Poder Judiciário, 4 de octubre de 2005. Comentario en: De santa gordilho, Heron José y De almeida Silva, Tagore Trajano Habeas copus para os grandes primatas en Revista do Instituto do Direito Brasileiro Año 1 Nro 4 (2012)

${ }^{37}$ Juzgado Contencioso, Administrativo y Tributario Número 4, "Asociación de Funcionarios y Abogados por los Derechos de los Animales y otros c/ Gobierno de la Ciudad Autónoma de Buenos Aires s/ amparo" 21.10.2015. Expte. A2174-2015/0.

38 Franco, Dabel Leandro y Cencha, Evelyn El abordaje de la "cuestión animal" en la perspectiva del buen vivir: un análisis de las constituciones de Ecuador y Bolivia en Derecho para Innovar Diario Ambiental No 104 (2016) p. 1-2. 
animales destinados a la alimentación humana estén sanos y sean criados en un entorno saludable, lo cual se acerca más a una postura reformista y a los debates sobre el bienestar animal. Esta perspectiva es importante al interior de la Unión Europea, y de parte de algunos Estados miembros. ${ }^{39}$

En el caso de Bolivia, el artículo 33 de la Constitución Plurinacional refiere al derecho a un ambiente sano y a la tutela hacia otros seres vivos para que se puedan desarrollar de manera normal y permanente, lo que también puede configurarse como un insumo para pensar en la cuestión específicamente animal.

Entre estos procesos regionales, el propio recorrido del campo legal argentino y los interrogantes que comienzan a proliferar a través de demandas judiciales de distinto tipo, podría afirmarse que existe una conjunción de discursos. Algunos provenientes del derecho animal, otros que se alinean con la consolidación de una dimensión colectiva del derecho privado y aquellos que se enlazan con perspectivas bio/eco-céntricas y que han cobrado importante visibilidad de la mano de procesos de países sudamericanos.

\section{CONClusiones}

La revisión de estos cuerpos legales que revisten centralidad en el ordenamiento jurídico argentino en tanto reguladores de las relaciones entre las personas y, a su vez, entre las personas y "las cosas" permiten identificar aportes tendientes a problematizar el estatuto jurídico de los animales no humanos, a la vez que conducen a reactivar debates del pasado, hoy reeditados a la luz del contexto local y regional.

Estos últimos refieren al modo en que los humanos nos relacionamos con la naturaleza y/o con los animales no humanos lo que, a su vez, recibe diferentes traducciones en el campo regulatorio: animales en tanto cosas, animales como seres sensibles, Madre Tierra, Pachamama como sujeto de derecho.

Ciertamente, en Argentina, las controversias en torno a una posible reforma del estatuto jurídico del animal no encontraron espacio en el marco de la última reforma del Código Civil, así como, tampoco, la postura que abreva por el reconocimiento de los animales en tanto sujetos. Sin embargo, como observamos anteriormente, se han incorporado otras herramientas jurídicas que se presentan como puntos de apoyo para repensar el estatuto animal. Nos referimos, especialmente, a la preocupación por dotar de una dimensión colectiva al derecho privado que, entre otras, se ve traducida en el mencionado artículo 240.

39 Ver nota al pie n. 29. 
La interpretación y el uso que se realice de este nuevo insumo al interior de nuestro ordenamiento jurídico permitirán delinear mejor su significado y su potencialidad. Mientras esto suceda, no es menor la posibilidad de contribuir a las diferentes perspectivas, cosmovisiones, que integran, no sin dificultades, un diálogo necesario y en curso, y que pueden, también, convertirse en una renovada oportunidad para volver sobre el debate en torno al capitalismo, las desigualdades sociales y el lazo solidario con la naturaleza y con los animales en particular.

Esto implica, en paralelo, un desafío por cuidar que este espacio emergente de reflexiones en nuestro país no termine convirtiéndose en un desencuentro con problemáticas de ineludible relevancia.

\section{BiBLIOGRAFÍA}

Berros, María Valeria Breve contextualización de la reciente sentencia sobre el habeas corpus en favor de la orangutana Sandra: entre ética animal y derecho en Revista de Derecho Ambiental No 41 (2015).

Burgat, Florence Res nullius, l'animal est objet d'appropriation en Archives Philosophiques du Droit No 38 (1993).

Cifuentes, Santos. Código Civil Comentado y Anotado. T.II. (Buenos Aires, La Ley, 2008).

Fleitas, Código Civil Proyecto de A.T. de Fleitas. T. III, Trad. Pons Arturo (Buenos Aires, Editorial Revista Nacional, 1901).

De Santana Gordilho, Heron José y De Almeida Silva, Tagore Trajano. Habeas copus para os grandes primatas en Revista do Instituto do Direito Brasileiro Año 1 No 4 (2012).

Demogue, René. Notions fondamentales de droit privé. Essai critique (Paris, Libraire nouvelle de droit et de jurisprudence, 1911).

Enciclopedia Jurídica Omeba. T. I. (Buenos Aires, Editorial bibliográfica Argentina, 1954a).

Enciclopedia Jurídica Omeba. T.V. (Buenos Aires, Editorial bibliográfica Argentina, 1954b)Enciclopedia Jurídica Omeba. 1959. T.II. (Buenos Aires, Editorial bibliográfica Argentina, 1959).

Falbo, Anibal \& Esain, José El Código Civily Comercial y el ambiente en Revista Código Civil y Comercial La Ley Año 1. Nro 2. (2015).

Francione, Gary. Animals, property, and the law. (Philadelphia, Temple University Press, 2007).

Franco, Dabel Leandro \& Cencha, Evelyn El abordaje de la "cuestión animal" en la perspectiva del buen vivir: un análisis de las constituciones de Ecuador y Bolivia en Derecho para Innovar Diario Ambiental Nro 104 (2016)

Garrone, J. A. Diccionario Manual Jurídico (Buenos Aires, Abeledo Perrot, 2008).

GolDSCHMID W. Introducción Filosófica Derecho, la teoría trialista del mundo jurídico y sus horizontes (Buenos Aires, Depalma, 1980)

HaIdAR, Victoria \& BerRos, María Valeria Entre el sumak kawsay y la "vida en armonía con la naturaleza": disputas en la circulación y traducción de perspectivas respecto de 
la regulación de la cuestión ecológica en el espacio global en Revista Theomai Estudios Criticos sobre Sociedad y Desarrollo, Año 15, No 32 (2015)

Hermitte, Marie- Angèle Le statut de la diversité biologique en Droit et société, $n^{\circ} 10$ Pratiques de recherche, questions théoriques et problèmes épistémologiques sur le droit et la société (1988).

LAFAILle, Héctor. Curso de derechos reales, vol.2. (Buenos Aires, Ghio, 1925).

Llambias, Joaquin Manual de derecho civil. Obligaciones (Buenos Aires, Abeledo Perrot, 1997).

Le Quang, Mathieu \& Vercoutère, Tamia Ecosocialismo y buen vivir. Diálogo entre dos alternativas al capitalismo (Quito, Cuadernos Subversivos IAEN, 2013).

REgan, Tom The case for animal rights (California, University of California Press, 2004).

SAGARNA, Fernando, Responsabilidad civil por daños causados por animales (Buenos Aires, Depalma, 1998)

Singer, Peter Animal Liberation. Towards an end to human's inhumanity to animals (New York, HarperCollins, 1977).

Singer, Peter Libération animal ou droits des animaux? en Philosophie animale. Différence, responsabilité el communauté. Afeissa, H.S. et J. B. JeAngène Vilmer (Paris, Vrin, 2010)

STONE C. Should trees have standing? Toward Legal Rights for Natural Objetcs en So, Cal. L. Rev. 45:450. (1972).

TAYLOR, Paul. Respect for nature. A theory of environmental ethics (Princeton, Princeton University Press, 1989).

Tuck, Richard Natural Rights Theories: Their Origin and Development (Cambridge University Press, 1982).

Zaffaroni, Eugenio. La Pachamama y el humano (Buenos Aires, Ediciones Colihue, 2012)

Jurisprudencia citada

Juzgado Contencioso, Administrativo y Tributario Número 4, 2015/10/21 "Asociación de Funcionarios y Abogados por los Derechos de los Animales y otros c/ Gobierno de la Ciudad Autónoma de Buenos Aires s/ amparo"

Cámara de Apelaciones en lo Penal, Contravencional y de Faltas Causa No 1700106-00/13 "Incidente de apelación en autos G. B., R. s/inf. Ley 14346".

Cámara Federal de Casación Penal, Sala II, 2014/12/18, Orangutana Sandra s/ recurso de casación.

Cámara Civil y Comercial de Trenque Lauquen, 1991/02/12, Jurisprudencia Argentina, 1992-II-437.

Cámara Civil, Comercial, Laboral y de Paz de Curuzú Cuatiá, 1994/08/19, Jurisprudencia Argentina, 1994-IV-485.

Cámara Civil y Comercial de Bahía Blanca, Sala I, 1998/03/16, La Ley Buenos Aires, 1999-691.

Cámara Civil y Comercial de Morón, sala I, 2004/11/11, La Ley Buenos Aires, 2006-536.

Cámara Civil y Comercial de la Tercera Nominación de Córdoba, 2007/10/18, La ley online. 